\title{
PENERAPAN SAK-EMKM PADA KESENIAN JARANAN TURONGGO BIMO KERTOSONO SEBAGAI SIMBOL BUDAYA
}

\author{
Martinus Sony Erstiawan \\ Program Studi Akuntansi \\ Universitas Dinamika Surabaya \\ Raya Kedung Baruk No. 98 Surabaya \\ martinus@dinamika.ac.id
}

\begin{abstract}
Art groups that have the soul of art in Indonesia are a group of micro, small, and medium entities (EMKM) that can use financial accounting standards for micro, small, and medium entities (SAK-EMKM). One of them is the art group which is still a symbol of cultural preservation, namely jaranan art. Financial management (recording, presentation, and disclosure) in the art of the networking requires the intention and practice as often as possible, so as to produce a simple financial report following accounting standards in force in Indonesia. This essay has the purpose of using a descriptive study of the application of SAK-EMKM to be applied to arts groups in Indonesia.
\end{abstract}

Keywords: accounting standards, micro, small, and medium entities, jaranan arts.

\begin{abstract}
ABSTRAK
Kelompok kesenian yang memiliki jiwa seni yang ada di Indonesia merupakan kelompok entitas mikro, kecil, dan menengah (EMKM) yang dapat menggunakan standar akuntansi keuangan entitas mikro, kecil, dan menengah (SAK-EMKM). Salah satunya adalah kelompok kesenian yang masih menjadi simbol pelestarian budaya, yaitu kesenian jaranan. Pengelolaan keuangan (pencatatan, penyajian, dan pengungkapan) dalam kesenian jaranan diperlukan niat dan latihan yang sesering mungkin, sehingga menghasilkan laporan keuangan sederhana mengikuti standar akuntansi yang berlaku di Indonesia. Sari tulisan ini memiliki tujuan menggunakan kajian deskriptif terhadap penerapan SAK-EMKM untuk dapat diterapkan pada kelompok kesenian yang ada di Indonesia.
\end{abstract}

Kata Kunci: standar akuntansi, entitas mikro, kecil, dan menengah, kesenian jaranan. 


\section{PENDAHULUAN}

Manusia merupakan lambang atau simbol dalam berakhlak, memiliki budi pekerti, kepercayaan, hati nurani, budaya, dan pikiran. Kebudayaan diciptakan oleh manusia sebagai sebuah simbol kepercayaan terhadap lingkungan sekitar dalam merefleksikan diri kepada sang pencipta agar mengikuti ajaran-Nya. Tingkah laku dapat mengubah seseorang mengikuti budaya yang digunakan sebagai identitas Negara Kesatuan Republik Indonesia (NKRI).

Keberagaman budaya di Indonesia dapat meningkatkan taraf hidup masyarakat sekitar dengan menambah destinasi objek wisata dan sebagai tempat hiburan bagi masyarakat sekitar maupun yang berada dalam kedaulatan Negara Kesatuan Republik Indonesia (NKRI). Objek wisata dan pagelaran budaya yang dilakukan pada objek wisata dapat menambah penghasilan bagi masyarakat sekitar maupun menjadi pendapatan daerah tersebut.

Berkembangnya tempat destinasi dan objek pariwisata serta pagelaran budaya dapat mempengaruhi sektor selain wisata diantaranya adalah sektor usaha mikro, kecil, dan menengah (UMKM), industri kecil tekstil, sepatu, baju, tas, pernakpernik, oleh-oleh, perdagangan, peternakan, pertanian, rumah makan, dan tempat penginapan dapat berjalan beriringan menjadikan tempat destinasi budaya tersebut menjadi ciri khas objek wisata.

Pagelaran seni budaya jaranan dilakukan pada kegiatan atau upacara resmi dan menjadi daya tarik bagi masyarakat sekitar ataupun wisatawan untuk melihat secara langsung tradisi, keunikan, keanekaragaman budaya atas hasil buatan manusia. Seni budaya jaranan dikelola oleh pegiat atau seseorang yang memiliki pemahaman terhadap simbol-simbol budaya, cerita perkembangan budaya daerah sekitar Jawa Timur, khususnya pada kesenian jaranan.

Mengelola kesenian jaranan tidaklah mudah, butuh tenaga ekstra memanfaatkan waktu, mulai dari menerima tawaran bermain (pagelaran) dengan aktivitas tawar menawar harga, memastikan tujuan pagelaran, latihan rutin untuk memupuk kerjasama tim antara penari dan pemusik, mengelola keuangan untuk menggaji diri sendiri, dan aset. Mengelola keuangan mulai dari pencatatan pemasukan dan pengeluaran perlu dilakukan sebagai upaya untuk dapat mengetahui uang tunai setiap waktu dan dapat digunakan untuk menghidupi kesenian jaranan yang ada, serta pengakuan akuntansinya dapat bermanfaat pada aktivitas kesenian jaranan. Pengelola kesenian jaranan Bapak (Bopo) Wahyu Hidayat S.Sn., M.Pd. sebagai pemilik/pengelola jaranan Turonggo Bimo, sejauh ini tidak melakukan pencatatan keuangan baik pencatatan pemasukan maupun pengeluaran sehingga tidak dapat diketahui pengeluaran dan pemasukan dari mana saja dan untuk apa saja. Akibatnya dalam mengelola keuangan kesenian jaranan tidak mengetahui usaha yang dilakukan menguntungkan atau tidak sama sekali atau bahkan mengalami kerugian. Pemilik dapat memprediksi tentang keluar masuknya penghasilan dan biaya tanpa melakukan kegiatan pencatatan di atas kertas.

Pencatatan kegiatan usaha dilakukan dari hari ke hari, mingguan, dan bulanan berdasarkan transaksi yang diperoleh. Pencatatan dilakukan setiap periodenya agar dapat menghasilkan laporan keuangan sederhana yang mencakup kegiatan seluruh kegiatan usaha berdasarkan tata kelola keuangan pada pelaku pekerja seni. Dengan demikian pengelolaan keuangan kesenian jaranan dapat menerapkan pencatatan 
akuntansinya berdasarkan SAK - EMKM. Tujuan dan manfaat dengan adanya penerapan penyajian laporan keuangan berbasis SAK - EMKM dapat mengatur dan mengelola dengan baik keuangan yang ada, dapat memperoleh informasi atas penyajian keuangan yang disusun secara detail sehingga informasi yang dihasilkan merupakan informasi yang dapat dipertanggunjawabkan atas dirinya sendiri dalam menyajikan laporan keuangan.

\section{SAK-EMKM}

Penyajian laporan keuangan berdasarkan SAK - EMKM (Ikatan Akuntan Indonesia, 2018) berupa mensyaratkan penyajian jujur atas pengaruh transaksi, peristiwa, dan kondisi lain yang sesuai dengan definisi dan kriteria pengakuan aset, liabilitas, penghasilan, dan beban. Penyajian yang wajar pada laporan keuangan bertujuan untuk (i) relevansi yang digunakan pengguna untuk pengambilan keputusan, (ii) representasi tepat dapat disajikan bebas dari kesalahan material dan bias, (iii) keterbandingan, dapat dibandingkan laporan keuangan antar periode, (iv) keterpahaman, di mana informasi yang disajikan dapat dengan mudah dipahami oleh pengguna.

\section{Akuntansi, dan Laporan Keuangan}

Akuntansi merupakan bahasa bisnis (Horngren and Harrison, 2007). Hal yang sama dikatakan pula oleh Kusdewanti, et al. (2014) yang menyebutkan bahwa akuntansi sebagai bahasa bisnis dalam logika globalisasi, semestinya mengikuti arah praktik bisnis yang mengglobal. Sedangkan Kieso et al. (2014) dalam Martani (2016) menyatakan bahwa akuntansi merupakan suatu sistem dengan input data/informasi dan output berupa informasi dan laporan keuangan yang bermanfaat bagi pengguna internal maupun eksternal entitas. Sebagai sistem, akuntansi terdiri atas input yaitu transaksi, proses yaitu kegiatan untuk merangkum transaksi berupa laporan keuangan.

Laporan keuangan menurut SAK EMKM (Ikatan Akuntan Indonesia, 2018) menyatakan bahwa tujuan laporan keuangan untuk menyediakan informasi posisi keuangan dan kinerja keuangan suatu entitas yang bermanfaat bagi sejumlah besar pengguna dalam pengambilan keputusan ekonomi atau siapapun yang tidak dapat meminta laporan keuangan khusus untuk memenuhi kebutuhan informasi tersebut.

\section{Metode Pencatatan Keuangan}

Menurut Ardiyos (2015) pencatatan keuangan terdiri dari 2 (dua), yaitu (a) Cash Basis Accounting Method (metode akuntansi dasar kas) yang merupakan metode pencatatan di mana pendapatan dan beban baru diakui apabila telah diterima atau dibayar secara tunai/kas, bukan ketika pendapatan telah dihasilkan atau beban telah terjadi, atau bisa disebut metode ini berkaitan dengan aliran kas masuk dan aliran kas keluar. (b) Accrual Basis Accounting Method (metode akrual dasar akuntansi) yang merupakan suatu metode akuntansi yang mengakui pendapatan dan beban berdasarkan pertimbangan apakah transaksinya telah terjadi atau belum. Pendapatan akan diakui jika aktivitas yang berkaitan dengan penjualan barang dan atau jasa telah selesai dilakukan secara lengkap. Sedangkan beban akan diakui apabila transaksi terkait dengan penggunaan barang dan jasa telah selesai 
dilakukan. Jadi pengakuan pendapatan dan beban pada metode akrual dasar akuntansi ini tidak melihat pada aliran kas masuk dan aliran kas keluar.

\section{Kesenian Jaranan Sebagai Simbol Budaya}

Kaulam (2012) menyatakan bahwa kesenian jaranan dilakukan orang dalam rangka upaya ritual (ritus) permohonan keselamatan dan keselarasan hidup. Menurut Kamus Besar Bahasa Indonesia (KBBI) simbol bermakna lambang atau melambangkan. Simbol berupa manifestasi dari roh leluhur sebagai media kegiatan ritual untuk mengatasi berbagai masalah kehidupan. Tarian jaranan menggunakan media tari berupa jaran kepang, kuda lumping, jathilan, atau tarian kuda diiringi instrumen gamelan, kendang, terompet khas (khusus), gong. Jaranan di Jawa Timur terdiri dari: a.) Jaranan Jawa, b.) Jaranan Pegon, c.) Jaranan Sentherewe, d.) Jaranan Breng, e.) Jaranan Buta atau Turangga Yakso (Prakoso, 2006: 3).

\section{Jaranan, Seni, Pertunjukkan, dan Makna Simbolis}

Jaranan berasal dari kata jaran yang berarti kuda jaranan yang merupakan tarian yang melukiskan gerak penunggang kuda. Para penari menaiki anyaman bambu berbentuk kuda seperti yang diungkapkan oleh Pigeud (1991: 21) yang menyatakan bahwa yang dimaksud dengan tari kuda adalah pertunjukan atau penampilan orang yang dengan mengepit anyaman yang dibuat dari bambu atau kulit, menirukan kuda, atau penunggang kuda. Tari-tarian yang bersifat kerakyatan termasuk jaranan telah berkembang dan merupakan pertunjukan yang cukup popular di seluruh pedesaan pada tahun 1930. Kelompok jaranan sangat beragam. Menurut Prakoso (2006: 13), terdapat 5 jenis di Jawa Timur: 1) Jaranan Jawa, 2) Jaranan Pegon, 3) Jaranan Sentherewe, 4) Jaranan Breng, 5) Jaranan Buta atau Turangga Yakso.

Menurut Soedarsono (2010: 118) seni pertunjukan memiliki fungsi yang sangat kompleks dalam kehidupan manusia. Fungsi dikelompokkan menjadi dua yaitu kelompok fungsi primer dan fungsi sekunder. Kelompok fungsi primer dibagi menjadi tiga berdasarkan atas 'siapa' yang menjadi penikmat seni pertunjukan. Fungsi primer tersebut antara lain: (1) sebagai sarana ritual, (2) sebagai ungkapan atau hiburan pribadi, (3) Sebagai presentasi estetis. Disebut fungsi sekunder, apabila seni pertunjukan bertujuan bukan untuk dinikmati, tetapi untuk kepentingan yang lain.

Bentuk penyajian sebuah pertunjukan seni selalu mempunyai makna simbolis, baik dari segi gerak, musik, tata rias busana, perlengkapan, dan properti. Seperti yang diungkapkan oleh Smith (1985: 29) istilah penyajian adalah simbolsimbol atau tanda dalam suatu pentas. Smith (1985: 29) juga menjelaskan bahwa simbol berasal dari kata Yunani yaitu "Symbolos" yang berarti tanda yang memberikan sesuatu kepada orang lain.

\section{Jenis dan Metode Pengumpulan Data}

Konsep metode pengumpulan data dengan melakukan observasi, mendata berkas yang dapat digunakan menjadi bukti, keseluruhan transaksi yang digunakan, wawancara kepada pengelola kesenian jaranan, menelisik transaksi/catatan keuangan, serta mewawancarai istri sebagai pengelola keuangan pada kesenian 
tersebut, serta merekap bukti transaksi yang terjadi saat itu. Pelaksanaan kegiatan ini menggunakan metode deskriptif kualitatif berdasarkan pedoman SAK - EMKM (Ikatan Akuntan Indonesia, 2018). Pada Gambar 1 yang terdapat dalam rerangka konseptual nampak bahwa pengelola kesenian jaranan perlu melakukan pencatatan, penyajian, dan pelaporan keuangan berbasis SAK - EMKM yang di dalamnya terdapat neraca, laporan laba rugi, dan laporan arus kas.

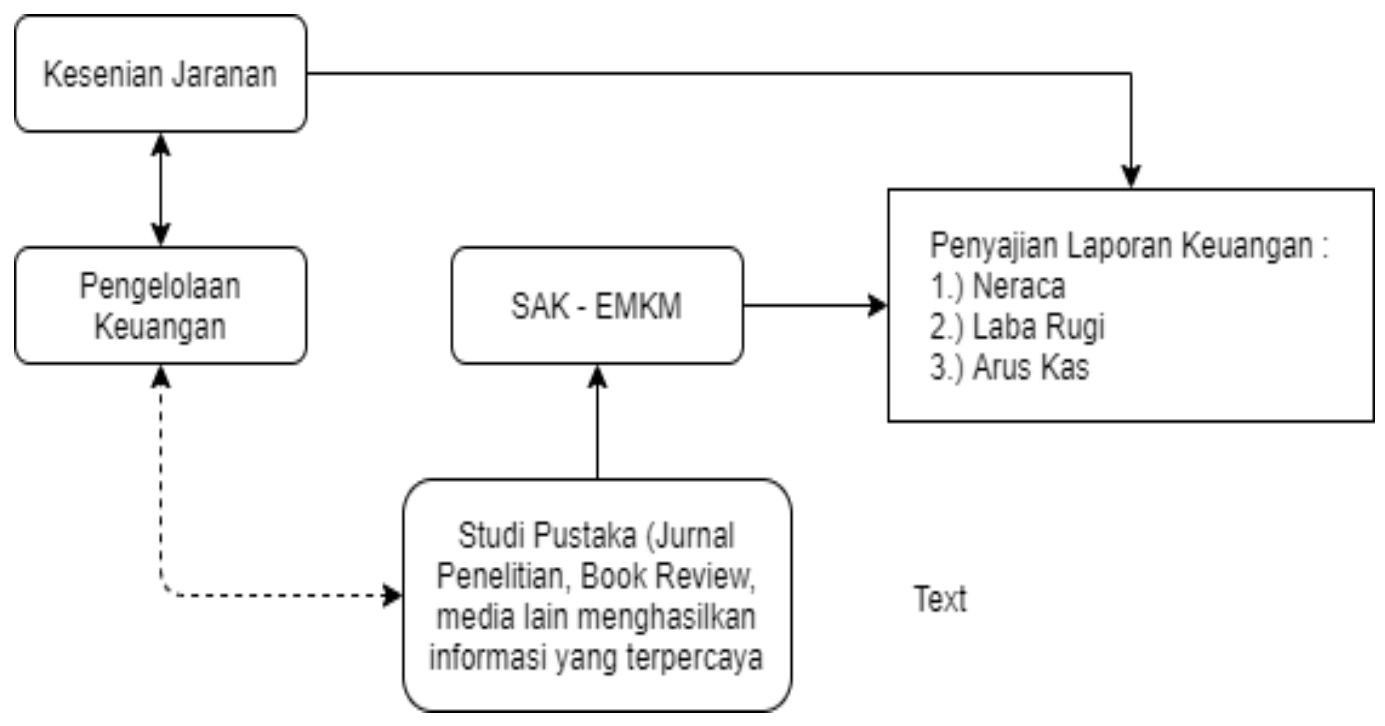

Gambar 1

Rerangka Konseptual

\section{PEMBAHASAN}

Penerapan berdasarkan SAK - EMKM pada laporan keuangan kesenian jaranan Turonggo Bimo Kertosono menurut pengakuannya menunjukkan bahwa sanggar kesenian Turonggo Bimo tidak mencari keuntungan dalam aktivitas penampilan kesenian jaranan. Modal yang diperoleh dalam mendirikan berasal dari usaha menyimpan/menabung uang diperoleh kisaran total modal Rp. 70.000.000,sampai dengan Rp. 80.000.000,-, bahkan bisa lebih. Kesenian jaranan berdiri sejak tahun 2014. Peralatan, kostum, properti, dan beberapa peralatan lain pada jaranan yang dimiliki dibayar secara mengangsur (menyicil).

Kesenian jaranan yang dikelola merupakan sebuah sarana kecintaan pengelola dalam kesenian jaranan dan terus berupaya melestarikan budaya. Pengelola kesenian jaranan menginginkan budaya jaranan dikenal oleh masyarakat luas, mulai dari pentas di beberapa tempat yang mengundang masyarakat umum hingga pagelaran komunitas kesenian jaranan area (lokasi) sekitar Jombang, Kertosono, Nganjuk, dan Kediri yang semuanya itu tidak memperoleh penghasilan/ keuntungan.

Pengelolaan kesenian jaranan dapat memperoleh keuntungan dari permintaan masyarakat terkait upacara besar bersih desa (ruwatan), upacara syukuran baik individu maupun kelompok masyrakat yang diminta untuk mengisi kegiatan sesuai permintaan dan kesepakatan bersama dengan yang sedang beracara. Nominal yang 
disepakati tergantung dari tema dan jumlah peralatan serta keseluruhan penampilan yang ditampilkan. Salah satu contoh bila menampilkan secara komplit peran yang ada di kesenian jaranan dan unsur-unsur yang didalamnya ikut tampil atau biasa disebut dengan paket komplit (barongan, jaran kepang, dupa komplit untuk mendoakan para leluhur, sajen/sesaji, peralatan musik, pengiring, sound system, dsb) terdapat kisaran harga yang perlu dibayarkan kepada pengelola kesenian jaranan yang seharusnya tercatat dalam pengeluaran.

Kegiatan kesenian jaranan yang selama ini ada tidak melakukan pencatatan keuangan, baik kegiatan yang telah dilakukan di masyarakat maupun kegiatan atas permintaan individu. Tidak melakukan pencatatan mulai dari pemasukan (keuntungan) dan biaya (pengeluaran) tidak tercatat dengan baik oleh pemilik jaranan. Menurut prinsip pemilik pengelola kesenian jaranan tidak penting untuk melakukan pencatatan transaksi keuangan. Dan sejauh ini tidak mengetahui apakah untung maupun rugi sehingga penyajian terhadap laporan keuangan kesenian jaranan Turonggo Bimo sejauh ini tidak dapat disajikan dengan baik.

Analisis terhadap pencatatan, pengakuan, pengukuran, dan penyajian dalam membentuk laporan keuangan yang terdiri dari jurnal, buku besar, neraca, laporan laba rugi tidak dilakukan oleh pengelola kesenian jaranan karena dianggap milik sendiri dan tidak mencari keuntungan, serta visi dan misi awal mendirikan kesenian jaranan berdasarkan atas kecintaan terhadap seni jaranan sebagai simbol pelestarian budaya yang kini terus diupayakan untuk dilestarikan dan sebagai wadah penyaluran bakat yang terpendam dalam diri pengelola. Walaupun begitu, seharusnya perlu tetap ada pencatatan keuangan secara sederhana mengikuti standar yang berlaku. Dengan demikian, dapat diketahui dengan baik oleh pemilik mengenai aset yang telah dimiliki, keuntungan, dan kerugian yang terjadi dari pengelolaan kesenian jaranan Turonggo Bimo.

\section{SIMPULAN}

Pengelola kesenian jaranan Turonggo Bimo belum sepenuhnya melakukan pencatatan transaksi keuangan sehingga dalam menyajikan pengukuran laporan keuangan berbasis SAK - EMKM tidak terwujud dengan baik. Hal ini disebabkan karena pengelola sekaligus pemilik merasa tidak membutuhkan laporan keuangan dengan alasan bahwa kegiatan tidak mencari keuntungan.

\section{SARAN}

Sebaiknya pengelola yang sekaligus juga menjadi pemilik dari kesenian jaranan Turonggo Bimo tetap melakukan pencatatan transaksi keuangannya agar dapat menyusun laporan keuangan seperti laporan perhitungan laba rugi dan neraca dengan menggunakan SAK - EMKM.

\section{DAFTAR PUSTAKA}

Ardiyos, 2015, Kamus Besar Akuntansi, Edisi 4, Alfabetis, Bandung.

BPS, 2015, Indikator Sosial Budaya, dan Pendidikan, Badan Pusat Statistik, Provinsi Jawa Timur. 
Daymon, Christine, and Immy Holloway, 2008, Metode-Metode Riset Kualitatif dalam Public Relation dan Marketing Communication, Diterjemahkan oleh: Cahya Wiratama, Bentang, Yogyakarta.

Hadi, Sumandiyo, 2007, Kajian Tari Teks dan Konteks, Pustaka Book Publisher, Yogyakarta.

Horngren, Charles T, and Walter T. Harrison, 2007, Accounting, 7th Edition, Pearson Education International.

Humardani, 1985, Kumpulan Kertas Tentang Kesenian, Proyek ASTI, Surakarta.

Ikatan Akuntan Indonesia, 2018, Standar Akuntansi Keuangan Entitas Mikro, Kecil, dan Menengah, Ikatan Akuntan Indonesia, Jakarta.

Indriani, Sinta Dewi, 2016, Studi tentang Sejarah Kesenian Jaranan Aswo Budoyo di Desa Wonoasri, Kecamatan Grogol, Kabupaten Kediri, Skripsi, Program Studi Pendidikan Sejarah, Universitas Nusantara PGRI, Kediri.

Kaulam, Salamun, 2012, Simbolisme dalam Kesenian Jaranan, Jurnal Seni Rupa, Vol. 1, No. 2.

Kusdewanti, Amelia, Achdiar Redy Setiawan, Ari Kamayanti, Aji Dedi Mulawarman, 2014, Akuntansi Bantengan: Perlawanan Akuntansi Indonesia Melalui Metafora Bantengan, dan Topeng Malang, Jurnal Akuntansi Multiparadigma, Vol. 5, No. 1, hal. 149 - 169.

Martani, Dwi, 2016, Akuntansi Keuangan Menengah Berbasis PSAK Konvergensi IFRS, Edisi 2, Buku 1, Salemba Empat.

Pigeud, 1983, Pertunjukan Rakyat Jawa, Terjemahan, Muhammad Husodo Pironggokusumo, 1991, Perpustakaan Reksa Pustaka, Surakarta.

Prakoso, Djoko, 2006, Kesenian Jaranan Kota Surabaya Studi Tentang Fungsi Kesenian Dalam Kehidupan Warga Musiman, Tesis, Tidak Diterbitkan, Pasca Sarjana STSI, Surakarta.

Pratiwi, Amelia Ika, dan Dwiyani Sudaryanti, 2016, Akuntansi Karapan Sapi pada Masyarakat Madura dengan Pendekatan Etnografi, Jurnal Jibeka, Vol. 10, No. 1.

Sedyawati, Edi, 2002, Indonesia Heritage (Seni Pertunjukan), Buku Antar Bangsa, Jakarta.

Smith, Jacqueline, 1985, Komposisi Tari: Sebuah Petunjuk Praktis Bagi Guru, Terjemahan Ben Soeharto, Ikalasti, Yogyakarta.

Soedarsono, 2010, Seni Pertunjukan Indonesia di Era Globalisasi, Gajah Mada University Press. 
Sugiyono, 2014, Metode Penelitian Kuantitatif, Kualitatif, dan Kombinasi (Mixed Method), Alfabeta, Bandung.

Suprapto, Yuni, Rusdarti, Muhammad Jazuli, 2015, Partisipasi Masyarkat dalam Pelestarian Warisan Budaya di Lasem, Journal of Educational Social Studies Vol. 4, No. 1, Program Studi Ilmu Pengetahuan Sosial, Program Pasca Sarjana, Universitas Negeri Semarang.

Trisakti, 2013, Bentuk dan Fungsi Seni Pertunjukkan Jaranan dalam Budaya Masyarakat Jawa Timur, Prosiding The $5^{\text {th }}$ International Conference on Indonesian Studies. Ethnicity, and Globalization, Jilid 2, ISSN 2087 - 0019, Fakultas Ilmu Pengetahuan Budaya Universitas Indonesia.

Undang-Undang Republik Indonesia Nomor 10 Tahun 2009 tentang Kepariwisataan.

Undang-Undang Republik Indonesia Nomor 5 Tahun 2017 tentang Pemajuan Kebudayaan.

Widhianningrum, Purweni, dan Nik Amah, 2014, Akuntansi Ketoprak: Sebuah Pendekatan Etnografi Masyarakat Seni Ketoprak di Pati, Jurnal Akuntansi, dan Pendidikan, Vol. 3, No. 2.

Wuryani, Emy, dan Wahyu Purwiyastuti, 2012, Menumbuhkan Peran Serta Masyarakat dalam Melestarikan Kebudayaan, dan Benda Cagar Budaya Melalui Pemberdayaan Masyarakat di Kawasan Wisata Dusun Ceto, Jurnal Setya Widya, Vol. 28, No. 2, hal. 147-153. 